\title{
STRUVITE CRYSTALLISATION AND RECOVERY USING A STAINLESS STEEL STRUCTURE AS A SEED MATERIAL
}

Water Research, Volume 41, Issues 11, June 2007, Pages 2449-2456.

K. S. Le Corre ${ }^{1}$, E. Valsami-Jones ${ }^{2}$, P. Hobbs ${ }^{3}$, B. Jefferson ${ }^{1}$, S.A. Parsons ${ }^{1 *}$

${ }^{1}$ Centre for Water Science, Cranfield University, Cranfield MK43 OAL, UK

*Tel: +44 (0)1234 754841, Fax: +44 (0)1234 751671

E-mail address: s.a.parsons@cranfield.ac.uk

${ }^{2}$ Department of Mineralogy, The Natural History Museum, Cromwell Road London, SW7

5BD, U.K

${ }^{3}$ Institute of Grassland and Environmental Research (IGER), North Wyke, Okehampton, Devon, EX20 2SB, UK

\begin{abstract}
A metallic system acting as a seed substrate has been designed and developed in order to assess its efficiency in recovering phosphorus as struvite. The device, consisting of two concentric stainless steel meshes, was immerged in the upper section of a pilot crystallisation reactor fed with synthetic liquors $\left(\mathrm{MgCl}_{2} \cdot 6 \mathrm{H}_{2} \mathrm{O}\right.$, $\mathrm{NH}_{4} \mathrm{H}_{2} \mathrm{PO}_{4}$ ) for two hours. Apart from soluble $\mathrm{PO}_{4}-\mathrm{P}$ removals which remained in the range 79-80 \% with or without application of the metallic system, it was found that under the specific operating conditions tested, the meshes were capable of accumulating struvite at a rate of $7.6 \mathrm{~g} \cdot \mathrm{m}^{-2} \cdot \mathrm{h}^{-1}$, hence reducing significantly the amount of fine particles remaining in solution from $302.2 \mathrm{mg} . \mathrm{L}^{-1}$ to $12 \mathrm{mg} . \mathrm{L}^{-1}$ when compared to trials without mesh.
\end{abstract}

Keywords: Seeded crystallisation; struvite; metallic accumulation system; P removal and recovery

\section{Introduction}

Blockage of pipes, breakdowns of centrifuges, pumps, heat exchangers and other pieces of equipment in contact with anaerobically digested effluents are typical consequences of the 
deposition in wastewater treatment plants of a white hard scale called struvite (Doyle and Parsons, 2002; Van Rensburg et al., 2003). Primarily considered as a problem to eliminate or inhibit (Borgerding, 1972; Doyle et al., 2003), struvite $\left(\mathrm{MgNH}_{4} \mathrm{PO}_{4} \cdot 6 \mathrm{H}_{2} \mathrm{O}\right)$ potential as a fertiliser has led wastewater companies to study its recovery (de-Bashan and Bashan, 2004).

The principles of struvite nucleation and growth as well as the efficiency of a variety of crystallisation reactors have been widely investigated and are well documented in the literature (Bouropoulos and Koutsoukos, 2000, Doyle and Parsons 2004; Le Corre et al., 2005; Von Münch and Barr, 2001; Stratful et al., 2004; Battistoni et al., 2005). However, the application of struvite crystallisation processes at full scale remains limited, with for instance Japan being the only country where complete phosphorus removal and recovery from anaerobically digested sludge liquors as struvite has been implemented and the resulting product sold to fertiliser companies (Gaterell et al., 2000; Ueno and Fujii, 2001). The reason why struvite crystallisation is not more widely applied is a combination of the unknown economic value of the process and the product, the need for $\mathrm{pH}$ control, and the formation of crystal fines (Adnan et al., 2003).

To optimise the size of the recovered struvite crystals, researchers have often tested crystallisation onto seed materials such as sand (Battistoni et al., 2002) or preformed struvite crystals (Shimamura et al., 2003). The impact of seeding can be seen on the final particle size distribution. To illustrate, Shimamura et al. (2003), who used struvite fines as a seed in their demonstrative reactor, observed a growth of particles from $0.79 \mathrm{~mm}$ to $1.18 \mathrm{~mm}$ in 12 days. However, if the use of a seed material to grow struvite has proved to be efficient, the operation of such processes requires strong mixing energy to insure the bed of seeds is continuously fluidised. As a result, when compared to a non-seeded crystallisation reactor, 
Battistoni et al. (2005) demonstrated that seeded crystallisation operative costs are increased due to extra pumping and air mixing energy.

As a substitute to conventional particle seed materials, Suzuki et al. (2005) recently reported the use of a metallic support to recover struvite from swine wastewater and showed the system could accumulate up to $1 \mathrm{~kg}$ of struvite after 30 days of submersion in their reactor. Studies on the scaling properties of struvite previously showed metallic materials to favour struvite deposition (Doyle et al., 2002). Furthermore, a recent study on the ability of a range of materials, including sand, struvite and a stainless steel mesh, demonstrated adhesion forces between struvite and a metallic surface to be the strongest (Le Corre et al., 2006a). The development of a simple, robust and innovative metallic system that could be integrated to any crystallisation reactor would therefore improve struvite recovery and offer an alternative to existing seeded fluidised bed reactors. Such systems could reduce energy consumption when compare to typical fluidised bed reactors filled with sand or struvite. A device has been designed at Cranfield University, and this paper presents results on its performances in recovering struvite formed from synthetic liquors.

\section{Material and methods}

\subsection{Reactor design and operating conditions}

A pilot scale crystallisation reactor was designed and developed at Cranfield University to study struvite nucleation and growth (Le Corre et al., 2006b). It was tested here for seeded crystallisation of struvite from synthetic liquors (Fig. 1). The process was composed of a $10 \mathrm{~L}$ reactor with two side sampling ports and a drain valve. A peristaltic pump injected simultaneously solutions of ammonium dihydrogen orthophosphate $\left(\mathrm{NH}_{4} \mathrm{H}_{2} \mathrm{PO}_{4} 0.2 \mathrm{M} /\right.$ Fisher 
Analytical Reagent Grade, UK) and magnesium chloride hexahydrate $\left(\mathrm{MgCl}_{2} \cdot 6 \mathrm{H}_{2} \mathrm{O} 0.05 \mathrm{M} /\right.$ Fisher analytical Reagent Grade, UK), prepared by dissolution of the corresponding solid compounds in deionised water.

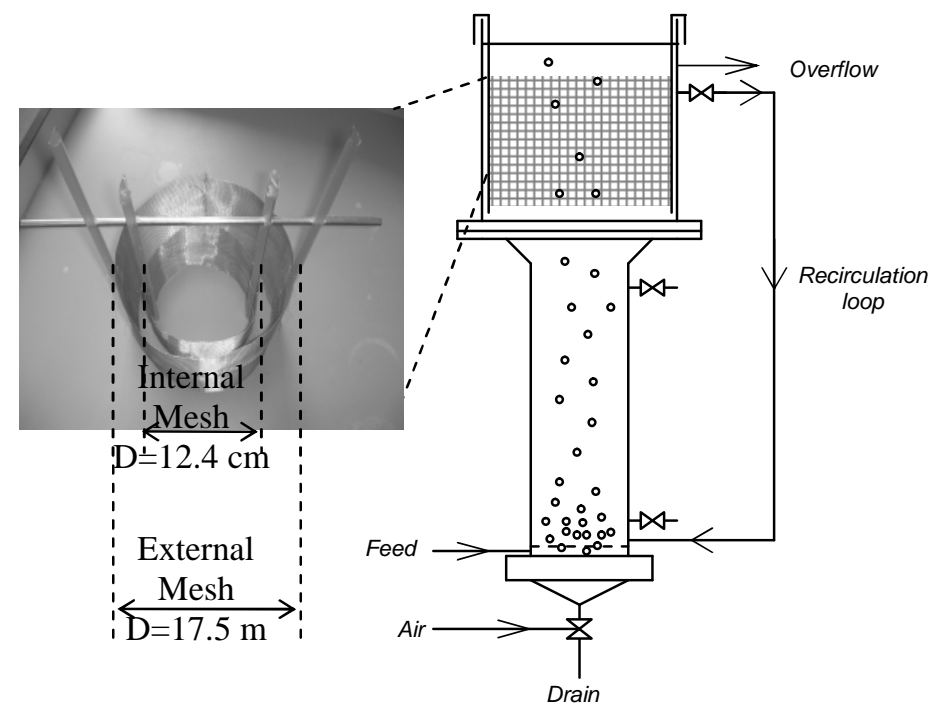

\begin{tabular}{|c|c|c|}
\hline$[\mathrm{Mg}]$ & $1.64 \mathrm{mM}$ & $2.3 \mathrm{~m} \mathrm{M}$ \\
\hline & \multicolumn{2}{|c|}{$\begin{array}{c}\mathrm{pH} 9 \\
\text { Air flow }=3 \mathrm{~L} \cdot \mathrm{min}^{-1} \\
\text { Recirculation= } 1.35 \mathrm{~L} \cdot \mathrm{min}^{-1}\end{array}$} \\
\hline $\begin{array}{l}\text { External } \\
\text { Mesh }\end{array}$ & $\nabla$ & $凶$ \\
\hline $\begin{array}{c}\text { Internal } \\
\text { mesh }\end{array}$ & $\nabla$ & 凶 \\
\hline $\begin{array}{c}\text { Combined } \\
\text { system }\end{array}$ & $\nabla$ & $\nabla$ \\
\hline
\end{tabular}

Fig. 1 - Process design and configurations tested.

Prior to mixing in the reactor, each solution was adjusted to $\mathrm{pH} 9$ with sodium hydroxide $(\mathrm{NaOH} 2 \mathrm{~N} /$ Fisher analytical reagent grade, UK) in stirred buckets. Both solutions were then transferred to the reactor. A pH probe was introduced in the reaction zone to control and maintain the $\mathrm{pH}$ constant during the crystallisation process. An upward air-flow and a liquid recirculation were adjusted (3-4 L. $\mathrm{min}^{-1}$ for air, and 1.35 to $1.5 \mathrm{~L} \cdot \mathrm{min}^{-1}$ for liquid) to ensure the mixing and growth of the particles formed so that they were always kept in suspension during the experiment. 
The experiments presented here were carried out at two different $\mathrm{Mg}$ concentrations $1.64 \mathrm{mM}$ and $2.3 \mathrm{mM}$, ratios $\mathrm{Mg}: \mathrm{N}: \mathrm{P}$ 1:2:2 and constant $\mathrm{pH}$, with and without the accumulation system. All experiments were conducted at room temperature over 120 minutes and repeated three times to ensure reproducibility of the results. During experiments, samples could be withdrawn for analysis from sampling ports situated on the side of the reactor at chosen height: top and bottom of the column shape part of the reactor and middle of the enlarged section.

2.2 Stainless steel mesh system design and configuration

A system composed of 2 concentric meshes was designed for use as a substrate to grow struvite. Both meshes were made of woven wire stainless steel $1 \mathrm{~mm}$ hole, $0.35 \mathrm{~mm}$ wire (Grade AISI 316 n $^{\circ} 1.4404$ - H\&B Wire Fabrications Ltd, UK) and dimensioned to fit in the enlarged section of the reactor (Fig. 1). The external mesh was $55 \times 14 \mathrm{~cm}$ and the internal mesh was $39 \times 9 \mathrm{~cm}$.

The meshes were independently removable to study the efficiency of the system under the various configurations summarised in Fig. 1.

\subsection{Sampling and analyses}

The evolution of struvite crystallisation in the reactor was followed by absorbance measurements. Samples were taken every 2 minutes during 30 minutes of crystallisation, then every 5 minutes until the $60^{\text {th }}$ minute and finally every 15 minutes during the last 60 minutes. Each sample was analysed for absorbance (6505 UV/Vis Spectrophotometer, Jenway, UK) at 
the specific wavelength of $385 \mathrm{~nm}$ determined by generating the optical adsorption spectrum for pure struvite crystals.

An analysis of variance (ANOVA) for this series of data was carried out at $\mathrm{t}=10 \mathrm{~min}$ and $\mathrm{t}=60 \mathrm{~min}$ to compare the impact of the four process configurations on struvite recovery.

At the end of each test $2 \mathrm{~L}$ of solution were withdrawn from the reactor and filtered through $0.2 \mu \mathrm{m}$ filters. Supernatants recovered were tested for soluble phosphate $\left(\mathrm{PO}_{4}-\mathrm{P}\right)$ and ammonium $\left(\mathrm{NH}_{4}-\mathrm{N}\right)$ by photometric methods adapted from standard methods, APHA, 1998 (Merck spectroquant cell tests, VWR International, Poole, UK) while the recovered struvite particles were dried at room temperature and weighted to assess the remaining quantity of struvite in suspension.

The submerged system was removed and left to dry at room temperature. Pictures of the meshes were taken to give a visual support of struvite accumulation onto the system as illustrated in Fig. 4. The meshes were also weighted to determine the mass of struvite accumulated. Struvite crystals were then recovered by light brushing for characterisation by SEM-EDS (Scanning Electron Microscope XL 30 SFEG, Philips, The Netherlands) and XRD (Powder X-ray Diffractometer D5005, Siemens, Germany).

\section{Results}

In order to evaluate any possible influence of the mesh system on soluble $\mathrm{PO}_{4}-\mathrm{P}$ and $\mathrm{NH}_{4}-\mathrm{N}$ removals, experiments undertaken over the range of mesh configurations tested were compared to experiments carried out under similar conditions of precipitation but without mesh (Fig. 2). Results showed that the different values of soluble $\mathrm{PO}_{4}-\mathrm{P}$ remaining in solution were similar either with or without mesh system incorporated in the reactor. To illustrate, at 
$[\mathrm{Mg}]=1.64 \mathrm{mM}, \mathrm{PO}_{4}-\mathrm{P}$ removals were $80 \%, 79 \%$ and $79 \%$ with the combined meshes, the internal mesh and the external mesh respectively where at a similar concentration the soluble $\mathrm{PO}_{4}-\mathrm{P}$ removal without mesh was $79 \%$. At a higher magnesium dose $(2.3 \mathrm{mM})$, the capacity of the reactor in removing phosphorus was also excellent, and was not affected by the immersion of the mesh as soluble $\mathrm{PO}_{4}-\mathrm{P}$ removals were $81 \%$ and $86 \%$ without mesh and with both meshes respectively.

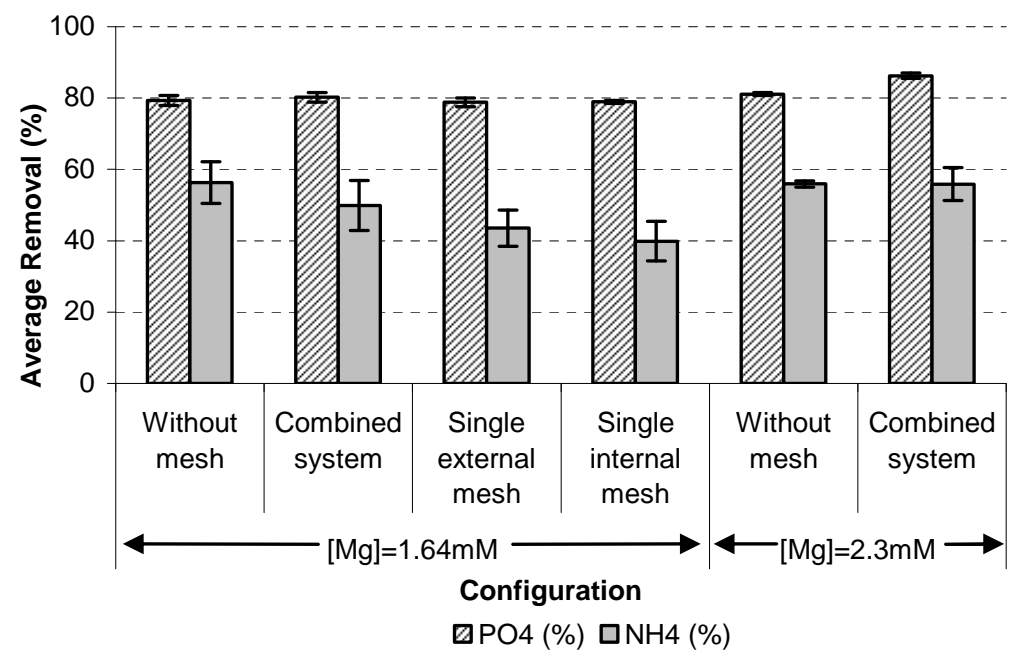

Fig. 2 - Average $\mathrm{PO}_{4}-\mathrm{P}$ and $\mathrm{NH}_{4}-\mathrm{N}$ percentage removals and standard deviations achieved under various reactor configurations.

With regards to levels of ammonium remaining in solution after $2 \mathrm{~h}$ of experiments, results showed that for similar conditions of precipitation $(1.64 \mathrm{mM}$ or $2.3 \mathrm{mM})$ the application of the metallic meshes in a combined configuration made no great difference when compared to crystallisation tests without it. For instance, at a magnesium concentration of $1.64 \mathrm{mM}, \mathrm{NH}_{4}$ $\mathrm{N}$ removals were $56 \%$ and $50 \%$ either without the system or with the combined one, while at a magnesium concentration of $2.3 \mathrm{mM} \mathrm{NH}_{4}-\mathrm{N}$ removals were similar without the system and with the combined meshes with values of $56 \%$. A slight increase of levels of ammonium remaining in solution only occurred when the meshes were submerged in an individual 
configuration as $\mathrm{NH}_{4}-\mathrm{N}$ removals were $43 \%$ and $39 \%$ with respectively the external mesh and the internal mesh.

Changes in absorbance during the crystallisation can be used to follow nucleation and crystal growth processes (Barrett and Parsons, 1998). The absorbance of a precipitating solution typically increases during nucleation due to crystal birth, while decreases as particles grow due to their settlement (Higashitani et al., 1993). In the present study, the absorbance measurements were then undertaken to follow struvite crystallisation progress and determine the impact of the meshes on recovery. Results were compared to crystallisation tests carried out under similar conditions without accumulation system (Fig. 3).

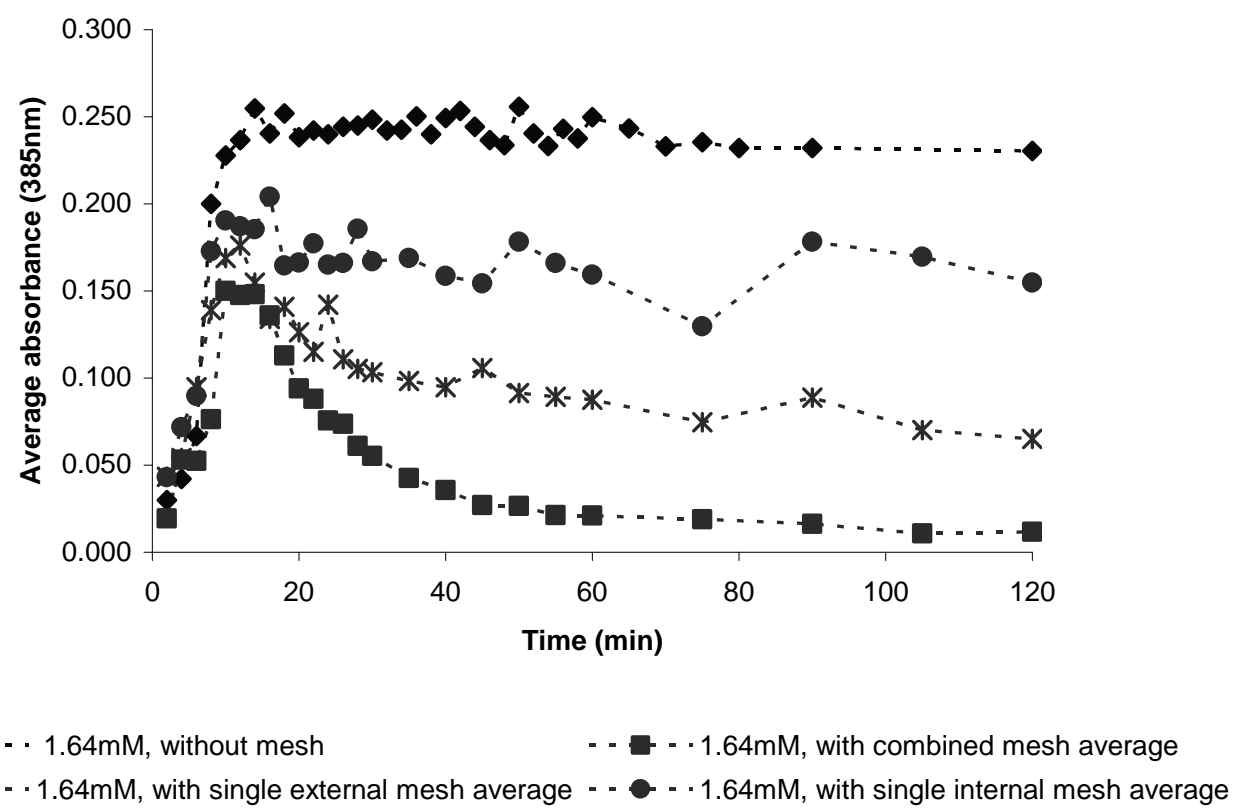

Fig. 3 - Average absorbance versus time for different configurations of the metallic mesh system.

For crystallisation tests at an initial $\mathrm{Mg}$ concentration of $1.64 \mathrm{mM}$ without the mesh, the absorbance profile showed that struvite nucleation occurred rapidly with absorbance increasing from $0.030 \pm 0.018$ to $0.255 \pm 0.028$ in less than $15 \mathrm{~min}$, and reaching a steady state for the remaining experimental time with an absorbance value of $0.230 \pm 0.007$ after $2 \mathrm{~h}$. 
With the mesh systems, absorbance measurements in the early stages of crystallisation (within $20 \mathrm{~min}$ ) followed a similar pattern indicating similar rates of nucleation, but after this period the absorbance decreased over the remaining experimental time. To illustrate, with the internal mesh, absorbance reached a maximum value of $0.204 \pm 0.006$ after $16 \mathrm{~min}$, and then decreased slowly down to $0.155 \pm 0.007$ after $2 \mathrm{~h}$ suggesting capture of some of the crystals onto the mesh. Visual observations of the mesh after $2 \mathrm{~h}$ reinforced this hypothesis as a white deposit was visible on its surface. Using only the external mesh, the absorbance profile increased to a maximum value of $0.176 \pm 0.023$ after $12 \mathrm{~min}$. The absorbance decreased then continuously and reached a final value of $0.065 \pm 0.012$ after $2 \mathrm{~h}$ indicating significantly less struvite crystals were suspended in solution.

When struvite was crystallised in presence of the combined meshes, the absorbance profile was similar to the one observed with the external mesh, but again even more struvite was captured as an absorbance peak at $0.150 \pm 0.026$ was observed after only $10 \mathrm{~min}$, and then measurements dropped down to $0.021 \pm 0.013$ in less than 60 min to finally stabilise around only $0.012 \pm 0.005$.

The statistical results of the analysis of variance (ANOVA Single Factor) on absorbance data obtained at $\mathrm{t}=10 \mathrm{~min}$ and $\mathrm{t}=60 \mathrm{~min}$ and an initial $\mathrm{Mg}$ concentration of $1.64 \mathrm{mM}$ confirmed the previous observations in that the application of the metallic mesh system under various configurations (i.e. Combined meshes, Single Internal mesh or single external mesh) had a significant impact on the absorbance of the solution remaining in the reactor, hence struvite recovery. At $\mathrm{t}=10 \mathrm{~min}$ the four configurations differed from each others as the calculated $\mathrm{F}$ value (7.19) exceeded the tabulated $\mathrm{F}_{\text {crit }}(\mathrm{p}=0.05)$ value of 4.066 , while after $60 \mathrm{~min}$ the difference became highly significant as the calculated $F$ was 259.34 compared to a $F_{\text {crit }}$ $(\mathrm{p}=0.05)$ of 4.066 and the probability that the calculated $\mathrm{F}$ value was obtained by chance alone was very small $\left(2 \cdot 63 \cdot 10^{-8}\right)$. 
Visual observations of the mesh (Fig. 4) showed that in a combined configuration the system accumulated a great amount of struvite particles, explaining the dramatic decrease in absorbance in the overall reactor. Interestingly, struvite adhered primarily on the external mesh of the system filling progressively holes situated in the bottom half of the mesh (Fig. 4A), while accumulation of struvite particles on the internal mesh was lower as a light white deposit was only visible on the wire surface of the mesh (Fig. 4B). As the internal mesh was positioned in the middle of the enlarged section right above the air diffuser, higher turbulence in this zone due to air may have then led to displacement of attached crystals.

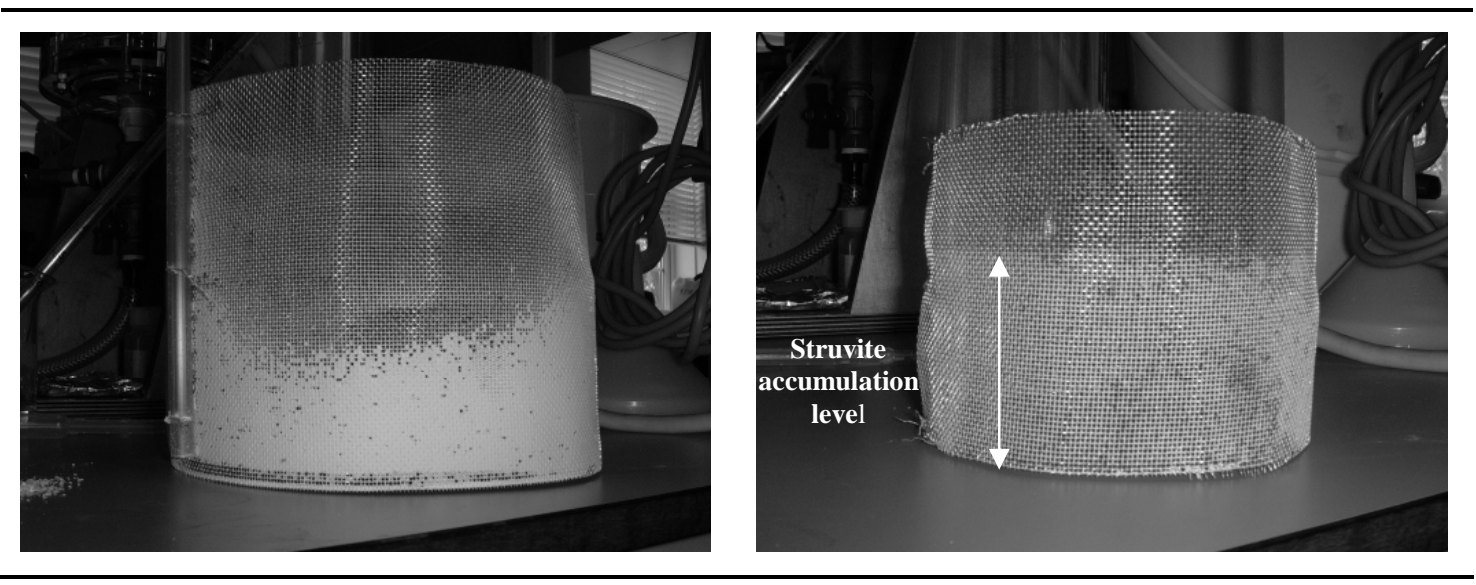

Fig. 4 - Pictures of the external (A) and internal (B) meshes used combined after $2 \mathrm{~h}$ of crystallisation at $[\mathrm{Mg}]=\mathbf{1 . 6 4} \mathbf{m M}$.

The amount of struvite particles remaining in solution after $2 \mathrm{~h}$ was also measured for the different operating conditions (Fig. 5).

At a $\mathrm{Mg}$ concentration of $1.64 \mathrm{mM}$, the amount of particles in suspension after 2 hours fell from $302.2 \pm 12.1 \mathrm{mg} . \mathrm{L}^{-1}$ with no mesh to $138.3 \pm 14.6,69.9 \pm 17.1$ and $12.2 \pm 11.1 \mathrm{mg} . \mathrm{L}^{-1}$ with the single internal mesh, the single external mesh and the combined system respectively. This corresponded to reductions of $96 \%, 77 \%$ and $54 \%$ of suspended particles with respectively the combined system, the single external mesh and the single internal mesh when 
compared to tests without mesh. These values correlated well with the absorbance values of $0.155 \pm 0.007,0.065 \pm 0.012$, and $0.021 \pm 0.013$ measured in solution after $2 \mathrm{~h}$ for respectively the single internal mesh, the single external mesh and the combined system.

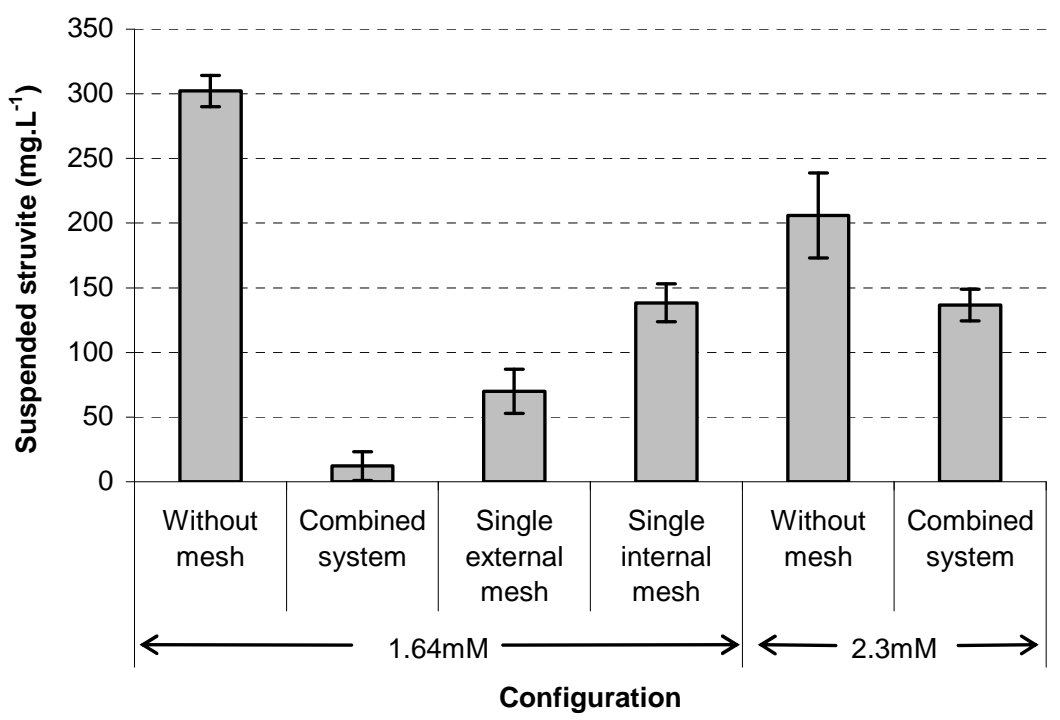

Fig. 5 - Average concentration of suspended struvite particles in solution after $2 \mathrm{~h}$, and standard devitations.

The efficiency of the system in removing suspended solids seemed to not only depend on the configuration tested but also on the magnesium stoichiometric dose. To illustrate, at high concentrations $(2.3 \mathrm{mM} \mathrm{Mg})$ in a combined configuration, there was still $136.6 \pm 12.4 \mathrm{mg} . \mathrm{L}^{-1}$ of suspended struvite after $2 \mathrm{~h}$ of experiments corresponding to a $34 \%$ of suspended solids removal. As a comparison, at $1.64 \mathrm{mM}$ in the same configuration, almost all of the suspended solids was captured by the system (Fig. 5). However, at $2.3 \mathrm{mM}$ the levels of suspended struvite particles in the control test without mesh were already lower than in the same conditions at a concentration of $1.64 \mathrm{mM}$. A settlement of particles at high concentrations may be at the origin of this difference and may explain lower removals of suspended struvite crystals. 
The amount of struvite recovered from the mesh has been quantified for each specific condition of precipitation previously tested and converted into rates of production per hour (Fig. 6).

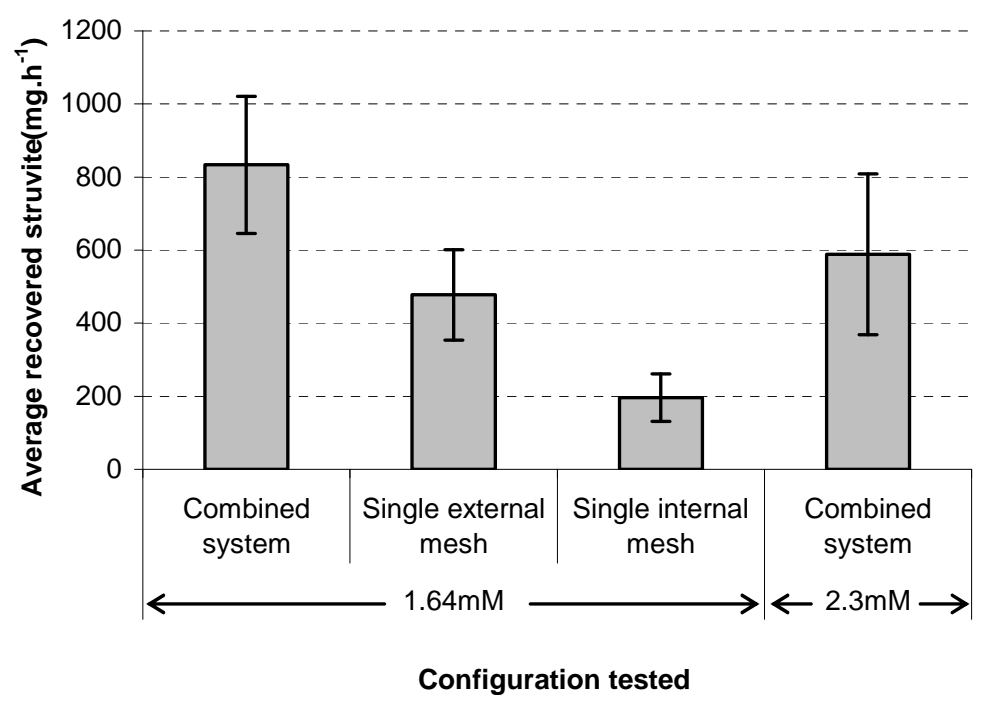

Fig. 6 - Effect of process running configurations on struvite recovery (Average results and standard deviations).

When submerged in the reactor for $2 \mathrm{~h}$, the metallic mesh could accumulate up to $1020 \mathrm{mg} \cdot \mathrm{h}^{-1}$ of struvite when the combined system was used at an Mg concentration of $1.64 \mathrm{mM}$, making this configuration the optimum one in recovering struvite. Indeed, under the other configurations tested the average quantities of struvite accumulated at the same concentration were reduced to $477 \pm 123 \mathrm{mg} \cdot \mathrm{h}^{-1}$ for the external mesh and $196 \pm 65 \mathrm{mg} \cdot \mathrm{h}^{-1}$ for the internal mesh. When linked to the actual surface of metal available for struvite to adhere on, the average accumulation rate of struvite under the optimum conditions (i.e. dual mesh system / $[\mathrm{Mg}]=1.64 \mathrm{mM}$ ) was of $7.6 \mathrm{~g} \cdot \mathrm{m}^{-2} \cdot \mathrm{h}^{-1}$. At $[\mathrm{Mg}]=2.3 \mathrm{mM}$, the potential to form greater quantities of struvite is higher due to higher concentrations of compounds available to form struvite. However, results revealed in that case that the mesh was not able to attach more 
particles as the accumulation rate was only $588 \pm 220 \mathrm{mg} \cdot \mathrm{h}^{-1}$ corresponding to an average rate of accumulation of $5.3 \mathrm{~g} \cdot \mathrm{m}^{-2} \cdot \mathrm{h}^{-1}$.

Finally, it was found that the position of the mesh in the reactor was influencing its capacity in recovering struvite. For instance, the internal mesh which was placed above the air diffuser was not able to accumulate high amounts of struvite when compared to the external mesh.

After drying of the meshes, the struvite was easily recoverable by gentle scraping. SEM-EDS analyses of the dried samples revealed particles present on each mesh surfaces were actually an agglomeration of single orthorhombic crystals (Fig. 7). As expected, the XRD (not shown) and EDS analyses also confirmed that the recovered product was pure struvite with EDS spectra showing the presence of $\mathrm{Mg}, \mathrm{P}$ and $\mathrm{O}$ indicating the metallic mesh characteristics had no influence on purity of the crystal formed (Fig. 7).

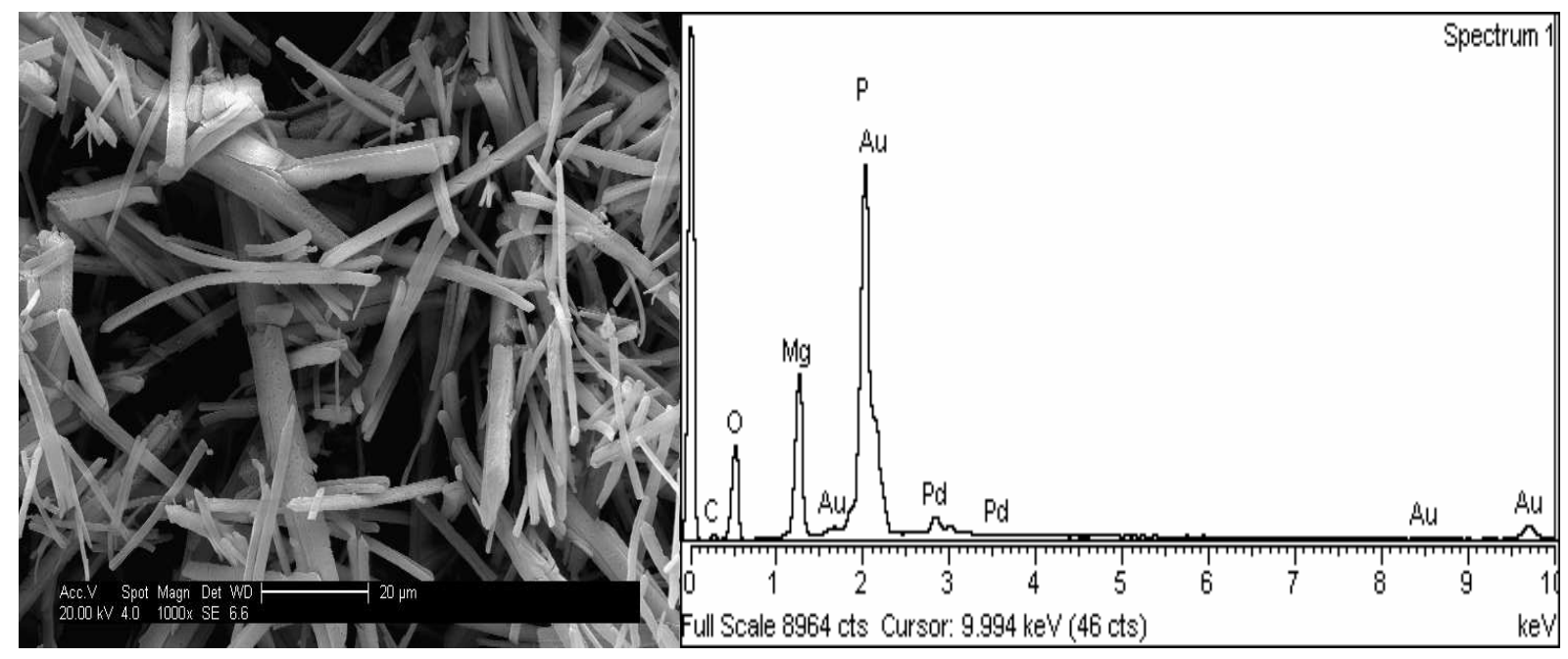

Fig. 7 - SEM image and EDS spectrum of the recovered struvite.

\section{Discussion}

In their study on the adhesion properties of potential seed materials for struvite crystallisation Le Corre et al. (2006a), demonstrated that struvite should adhere to a metallic surface. They measured the strength of adhesion between struvite and a range of surfaces and demonstrated 
the adhesion forces between struvite and a metallic surface were higher than between struvite and the other surfaces investigated (i.e. sand, recycled concrete aggregates and preformed struvite crystals). Those results were in accordance with previous works (Doyle et al., 2002) that have studied the scaling properties of struvite in pipes and other pieces of equipment in contact with wastewater effluents and demonstrated a strong affinity of metallic support for struvite deposition (Mohajit et al., 1989). Booram et al. (1975) in one of the first studies of struvite deposition in a wastewater treatment plant deduced that metallic interfaces acted preferentially as active growth site for struvite deposition. Later on, Doyle et al. (2002) confirmed that stainless steel coupons placed for $8 \mathrm{~h}$ in centrate liquors allowed significant adhesion of struvite with scaling rates in the range $0.4 \mathrm{~g} \cdot \mathrm{m}^{-2} \cdot \mathrm{h}^{-1}-5.4 \mathrm{~g} \cdot \mathrm{m}^{-2} \cdot \mathrm{h}^{-1}$ depending on the operating conditions. According to these observations a well designed system composed of stainless steel and submerged in a struvite crystallisation reactor should be able to act as a seed material to grow struvite.

The metallic system consisting of two circular meshes tested in the present study confirmed our expectations in that it was able to accumulate large amounts of struvite at its surface (i.e. up to $7.6 \mathrm{~g} \cdot \mathrm{m}^{-2} \cdot \mathrm{h}^{-1}$ using the combined system at a $\mathrm{Mg}$ concentration of $1.64 \mathrm{mM}$ ) in rather short times (2h). However, absorbance and suspended solids measurements suggested that rather than growing struvite at its surface as supposed from previously cited studies on the adhesive properties of struvite, the mesh was trapping crystals that formed in the reactor.

In the literature, only one study has explored and made use of the adhesive properties of metallic surfaces for intentional crystallisation of struvite. Suzuki et al. (2005) designed a rectangular stainless steel device for struvite crystallisation from swine wastewater. Their system which was immersed in the aeration column of a demonstrative reactor operating in a continuous mode recovered up to $1,037 \mathrm{~g}$ of struvite on its accumulation face after 30 days of operation. By comparison, considering the optimum struvite accumulation rate of $7.6 \mathrm{~g} \cdot \mathrm{m}^{-2} \cdot \mathrm{h}^{-1}$ 
calculated here to be constant, if the meshes had been submerged over 30 days in the pilot reactor running in a continuous mode, up to $602 \mathrm{~g}$ of struvite could have been theoretically recovered from the mesh. This is more than 1.5-fold lower than what Suzuki et al. (2005) observed but still promising when considering that this was achieved in synthetic liquors. Furthermore, rates of agglomeration on sand or struvite as seed material seem much lower than the rate observed on metallic supports. For instance, Shimamura et al. (2003) who precipitated struvite onto fine particles in real liquors, had rate of agglomeration (estimated from the increase in mean particle size they reported) of only $1.82 \mathrm{~g} \cdot \mathrm{m}^{-2} \cdot \mathrm{h}^{-1}$ after 12 days. The advantages of struvite crystallisation on a static support are numerous. Indeed, as stated by Stratful et al. (2004), one of the reason why wastewater companies have not adopted the struvite crystallisation technique, especially FBRs, to remove and recover phosphorus is related to their complex design and the need of qualified operators to constantly control and maximise their efficiency. Accumulation devices like the one used here could limit these problems as they are relatively simple to design and require very low maintenance. Moreover, recovery of struvite can simply be achieved by light scraping of the mesh. Suzuki et al. (2005) concluded that the ease of use and robustness of similar recovery systems would be particularly attractive for swine farmers. The utilisation of this type of processes would also decrease the risk of operational failures or reduction of the process efficiency that can be observed when crystallising struvite on granular materials. Ohlinger et al. (2000) have for example underlined that when using granular material as seed for struvite crystallisation in an FBR, the mass of particles increased due to growth and could provoke bulking of the media. To avoid this phenomenon, a part of the media needed to be refreshed periodically and this regeneration could affect the efficiency of the FBR in removing phosphorus. Shimamura et al. (2003) also indicated that with traditional FBRs, the growth of struvite crystals reduces their fluidisation, and limits the surface area available for its precipitation reducing then struvite 
recovery. Furthermore, in some cases the recovery of struvite on a regular basis can also require a temporary shutdown of the crystallisation process during the settlement of the product (Adnan et al., 2003), whereas the operation of the present reactor in a continuous mode would only require spare accumulation systems so that the fully loaded mesh could be replaced by a fresh one without having to stop all feeding and/or air pumps.

Battistoni et al. (2005) explained that operational costs of their fluidised bed reactor were increased because of the energy consumption linked to pumping equipments and costs of the raw seed material (i.e. sand). To illustrate, they indicated that struvite production using seed materials as sand would cost about $0.28 € . \mathrm{m}^{-3}$ including pumping energy and regeneration of seeds whereas without seed material the costs of production could be reduced down to 0.19 $€ . \mathrm{m}^{-3}$. It can be then assumed that the utilisation of the metallic mesh system which requires lower feeding and air flow rates than the one necessary to fluidise a bed of growing granular seed materials would also save energy significantly.

\section{Conclusion}

In the current work the performance of a stainless style mesh system acting as a seed substrate for struvite crystallisation in synthetic liquors has been investigated. Various tests in different configurations demonstrated that the system combining two concentric meshes placed in the enlarged section of the pilot scale crystallisation reactor was able to accumulate struvite at a rate of $7.6 \mathrm{~g} \cdot \mathrm{m}^{-2} \cdot \mathrm{h}^{-1}$ under optimum conditions of precipitation and to achieve excellent $\mathrm{PO}_{4}-\mathrm{P}$ removals up to $81 \%$. The mesh was particularly efficient when placed on the edge of the enlarged section of the reactor, as it was showed that mixing energy could be responsible of crystals detachment from the mesh. Finally, rather than growing struvite directly on its surface, the mesh system is thought to capture struvite crystal already formed in solution. 
Further investigations in real liquors are currently being undertaken at Cranfield University. However, the conclusions resulting from this work and the comparisons with other seeded processes showed that a struvite crystallisation reactor combined with the current metallic system could be a solution for maximising phosphorus recycling in wastewater treatment plants.

\section{Acknowledgement}

The authors would like to thank Cherub and Severn Trent Water for their sponsorship of this work.

\section{REFERENCES}

Adnan, A., Mavinic, D.S. and Koch, F.A. (2003) Pilot-scale study of phosphorus recovery through struvite crystallization-examining the process feasibility. Journal of Environmental Engineering Sciences 2, 315-324.

APHA (1998). Standard methods for the examination of water and wastewater, $20^{\text {th }}$ Edition. American Public Health Association / American Water Works Association / Water Environment Federation, Washington DC, USA.

Barett, R.A. and Parsons, S.A. (1998) The influence of magnetic fields on calcium carbonate precipitation. Water Research 32, 609-612.

Battistoni, P., De Angelis, A., Prisciandaro, M., Boccadoro, R. and Bolzonella, D. (2002) P removal from anaerobic supernatants by struvite crystallisation: long term validation and 
process modelling. Water Research 36, 1927-1938.

Battistoni, P., Boccadoro, R., Fatone, F. and Pavan, P. (2005) Auto-nucleation and crystal growth of struvite in a demonstrative fluidized bed reactor (FBR). Environmental Technology 26, 975-982.

Booram, C.V., Smith, R.J. and Hazen, T.E. (1975) Crystalline phosphate precipitation from anaerobic animal waste treatment lagoon liquors. Transactions of the American Society of Agricultural Engineers, 340-343.

Borgerding, J. (1972) Phosphate deposits in digestion systems. Journal of the Water Pollution Control Federation 44, 813-819.

Bouropoulos, N.C. and Koutsoukos, P.G. (2000) Spontaneous precipitation of struvite from aqueous solutions. Journal of Crystal Growth 213, 381-388.

de-Bashan, L.E. and Bashan, Y. (2004) Recent advances in removing phosphorus from wastewater and its use as fertilizer (1997-2003), Water Research 38, 4222-4246.

Doyle, J.D. and Parsons, S.A. (2002) Struvite formation, control and recovery. Water Research 36, 3925-3940.

Doyle, J.D., Oldring, K., Churchley, J. and Parsons, S.A. (2002) Struvite formation and the fouling propensity of different materials. Water Research 36, 3971-3978. 
Doyle, J.D., Oldring, K., Churchley, J., Price, C. and Parsons, S.A. (2003) Chemical control of struvite precipitation. Journal of Environmental Engineering- ASCE 129, 419-426.

Doyle, J.D. and Parsons, S.A. (2004) Struvite scale formation and control. Water Science and Technology 49, 177-182.

Gaterell, M.R., Gay, R., Wilson, R., Gochin, R.J. and Lester, J.N. (2000) An economic and environmental evaluation of the opportunities for substituting phosphorus recovered from wastewater treatment works in existing UK fertiliser markets. Environmental Technology 21, 1067-1084.

Higashitani, K., Kage, A., Katamura, S., Imaj, K. and Hatade, S. (1993) Effects of a magnetic field on the formation of $\mathrm{CaCO} 3$ particles. Journal of Colloids and Interface Science 156, 9095.

Le Corre, K.S., Valsami-Jones, E., Hobbs, P. and Parsons, S.A. (2005) Impact of calcium on struvite crystal size, shape and purity. Journal of Crystal Growth 283, 514-522.

Le Corre, K.S., Valsami-Jones, E., Hobbs, P., Boyd, R.D., Jefferson, B. and Parsons S.A. (2006a) Influence of seed material characteristics on rapid struvite recovery. In: Understanding Struvite Crystallisation and Recovery. PhD Thesis, Centre for Water Science, Cranfield University, Cranfield, UK.

Le Corre, K.S., Valsami-Jones, E., Hobbs, P. and Parsons, S.A. (2006b) Impact of reactor operation on success of struvite precipitation from synthetic liquors. In: Understanding 
struvite crystallisation and recovery. $\mathrm{PhD}$ Thesis, Centre for Water Science, Cranfield University, Cranfield, UK.

Mohajit, X., Bhattarai, K.K., Taiganides, E.P. and Yap, B.C. (1989) Struvite deposits in pipes and aerators. Biological Wastes 30, 133-147.

Ohlinger, K.N., Young, T.M. and Schroeder, E.D. (2000) Postdigestion struvite precipitation using a fluidised bed reactor. Journal of Environmental Engineering 126, 361-368.

Shimamura, K., Tanaka, T., Miura, Y. and Ishikawa, H. (2003) Development of a high efficiency phosphorus recovery method using a fluidised-bed crystallized phosphorus removal system. Water Science and Technology 48, 163-170.

Stratful, I., Scrimshaw, M.D. and Lester, J.N. (2004) Removal of struvite to prevent problems associated with its accumulation in wastewater treatment works. Water Environment Research 76, 437-4199.

Suzuki, K., Tanaka, Y., Kuroda, K., Hanajima, D. and Fukumoto, Y. (2005) Recovery of phosphorus from swine wastewater through crystallization. Bioresource Technology 96, 1544-1550.

Ueno, Y. and Fujii, M. (2001) Three years experience of operating and selling recovered struvite from full-scale plant. Environmental Technology 22, 1373-1381.

Van Rensbourg, P., Musvoto, E.V., Wentzel, M.C. and Ekama, G.A. (2003) Modelling 
multiple mineral precipitation in anaerobic digester liquor. Water Research 37, 3087-3097.

Von Münch, E. and Barr, K. (2001) Controlled crystallisation for removing phosphorus from anaerobic digester sidestreams. Water Research 35, 151-159. 